\title{
Strategi Pengembangan Usahatani Sayuran Organik Kelompok Tani Cepoko Mulyo Kabupaten Boyolali
}

\author{
Strategy for Developing Organic Vegetable Farm of Cepoko Mulyo Farmers' Group Boyolali Regency
}

\author{
Galih Seno Samodro*, Yuliawati
}

Program Studi Agribisnis, Fakultas Pertanian dan Bisnis, Universitas Kristen Satya Wacana Salatiga

Corresponding author: 522013042@student.uksw.edu

\begin{abstract}
This research aims to: 1) analyze internal and external factors into strengths, weaknesses and threats and opportunities of farmers group Cepoko Mulyo in the development of organic vegetable farming, 2) Analyze and establish the main strategies that can be applied in the development of organic vegetable farming. The research was conducted on February to April 2018 in farmer group Cepoko Mulyo in Pandansari, Wonodoyo Village, Cepogo district, Boyolali regency of Central Java Province. The type of research used is descriptive research and the method used the survey method. Analysis of qualitative and quantitative descriptive data with IFE, EFE, IE, SWOT, and QSPM matrices. The result of the analysis shows that based on the IFE matrix the main strengths are vegetables with varying sizes of 0.287. The main weakness is the management of information systems that have not been good with a score of 0.172, while based on the EFE matrix the main opportunity is the association of organic farming with a score of 0.239 and the main threat is high competition level with other farms with a score of 0.234. Based on the QSPM analysis the suggested strategy is to cooperate with both central and local government in product marketing.
\end{abstract}

Keywords: internal and external factors, management strategic, organic vegetable, QSPM, SWOT

Cite this as: Samodro, G. S., \& Yuliawati. 2018. Strategi Pengembangan Usahatani Sayuran Organik Kelompok Tani Cepoko Mulyo Kabupaten Boyolali. Caraka Tani: Journal of Sustainable Agriculture. 33(2), 169-179. doi: http://dx.doi.org/10.20961/carakatani.v33i2.22874

\section{PENDAHULUAN}

Pertanian organik merupakan teknik budidaya pertanian yang mengandalkan bahan-bahan alami tanpa menggunakan bahan-bahan sintetis (Dlamini dan Kongolo, 2014). Tujuan utama pertanian organik adalah menyediakan produkproduk pertanian, terutama bahan pangan yang aman bagi kesehatan produsen dan konsumennya serta tidak merusak lingkungan (Sutanto, 2002). Gaya hidup sehat demikian telah melembaga secara internasional yang mensyaratkan jaminan bahwa produk pertanian harus beratribut aman dikonsumsi (food safety attributes), kandungan nutrisi tinggi (nutritional attributes) dan ramah lingkungan (eco-labeling attributes) (Sulistyana et al., 2014). Pangan yang sehat dan bergizi tinggi dapat diproduksi dengan metode pertanian organik (Yanti, 2005).

Kini produk pertanian organik semakin berkembang dan diminati oleh masyarakat, terbukti banyak petani yang beralih dari sistem pertanian konvensional ke pertanian organik. Menurut Khalimi (2010), penggunaan pupuk yang mengandung kimia sintetis pada tumbuhan dapat menimbulkan masalah kesehatan dan pencemaran lingkungan sehingga untuk mengatasi permasalahan tersebut digunakan pupuk organik. Pupuk organik ini dapat berupa kompos, pupuk kandang, pupuk hijau serta pupuk

\footnotetext{
* Received for publication August 11, 2018

Accepted after corrections October 9, 2018
} 
organik cair dan untuk bahan baku pupuk organik sangat mudah diperoleh karena memanfaatkan bahan-bahan seperti sampah organik yang berada di sekitar lingkungan (Irawati dan Salamah, 2013). Pupuk kandang yang berasal dari kotoran ayam, sapi dan kambing dapat digunakan dalam budidaya tanaman organik, namun diantara ketiga jenis pupuk tersebut pupuk kandang yang berasal dari kotoran sapi memiliki kandungan hara tertinggi (Baity et al., 2015). Pengaruh pemberian dosis pupuk organik memberikan hasil yang lebih tinggi pada jumlah umbi, berat umbi sampel, berat umbi per petak dan diameter umbi (Lathifah et al., 2017).

Menurut Muljaningsih (2011) diantara produk pertanian organik, sayuran merupakan salah satu produk pertanian organik yang paling disukai oleh konsumen setelah beras, artinya sayuran dianggap sebagai salah satu kebutuhan utama sebagai bahan pangan. Salah satu kelompok tani yang mengembangkan usahatani sayuran organik, adalah kelompok tani Cepoko Mulyo yang terletak di Dukuh Pandansari, Desa Wonodoyo, Kecamatan Cepogo, Kabupaten Boyolali. Kelompok tani ini sudah memiliki sertifikat organik yang dikeluarkan oleh Lembaga Sertifikasi Organik Seloliman (LeSOS) pada tahun 2016.

Beberapa kendala yang dihadapi kelompok tani Cepoko Mulyo dalam menjalankan kegiatan usahatani sayuran organik antara lain 1) belum ada insentif harga yang memadai untuk produsen produk pertanian organik, 2) perlu investasi mahal pada awal pengembangan karena harus melakukan proses konversi lahan dari pertanian konvensional ke pertanian organik yang benarbenar bebas dari penggunaan bahan kimia sintetis, 3) belum ada kepastian pasar, sehingga petani enggan memproduksi komoditas tersebut. Menurut Mayrowani (2012), kendala-kendala dalam pengembangan pertanian organik yang bersifat makro meliputi pasar dan kondisi iklim, sedangkan yang bersifat mikro adalah kendala yang dijumpai di tingkat usahatani khususnya petani kecil. Kendala ini juga yang dialami kelompok tani Cepoko Mulyo yaitu dalam hal pemasaran produk yang mereka hasilkan, namun menurut Effendi (2015) pemasaran yang berbasis pada kelestarian lingkungan merupakan sebuah pengembangan baru dalam dunia pemasaran dan merupakan sebuah peluang yang sangat strategis dan potensial yang akan memiliki keuntungan ganda bagi para pelaku bisnis dan juga masyarakat sebagai konsumen. Kendala lain yaitu sulit mendapatkan pelanggan di pasar tradisional karena harga sayur organik lebih mahal dibanding sayur non organik (Putra et al., 2015). Permintaan sayuran organik dipengaruhi harga. Semakin tinggi harga maka akan semakin sedikit jumlah permintaan sayuran organik (Silitonga dan Salman, 2014).

Akses pasar bagi petani sayuran organik masih belum terbuka sepenuhnya, maka diperlukan kerja sama kemitraan yang saling menguntungkan antara pengusaha dan petani sayuran organik yang difasilitasi oleh pihak lain seperti Kementerian Pertanian, perguruan tingi dan lembaga swadaya masyarakat (Hubeis et al., 2013). Faktor promosi serta lokasi berpengaruh positif namun tidak berpengaruh nyata terhadap keputusan pembelian sayur organik (Suardika et al., 2014).

Demi menghadapi tantangan tersebut, perbaikan-perbaikan terhadap berbagai komoditi hortikultura terus dilakukan dengan meningkatkan standar kualitas produk supaya semakin baik, aman dikonsumsi, harga terjangkau dan dapat diakses oleh seluruh lapisan masyarakat (Adiyoga, 1999). Meningkatnya tren konsumen terhadap produk-produk tanaman organik perlu diantisipasi dengan usaha-usaha kreatif untuk memecahkan masalah fluktuasi harga, kegagalan panen serta ketersediaan lahan (Gribaldi, 2009). Strategi untuk memenangkan persaingan secara berkesinambungan di pasar adalah keunikan nilai produk melalui pendekatan POAC (planning, organizing, actuating dan controlling) (Roosany et al., 2014).

Berdasarkan permasalahan tersebut, maka perlu diketahui keberadaan usaha sayuran organik dan strategi pengembangan usahatani serta bagaimana yang harus dilakukan kelompok tani Cepoko Mulyo agar kegiatan usahanya berlanjut. Strategi tersebut berfungsi untuk menjaga kuantitas dan kualitas hasil produk pertanian yang ASUH (Aman, Sehat, Utuh, Halal), sehingga dapat bersaing di pasar Nasional maupun Internasional. Penelitian ini bertujuan untuk mengidentifikasi dan menganalisis faktor internal dan eksternal yang menjadi kekuatan, kelemahan serta ancaman dan peluang kelompok tani Cepoko Mulyo dalam pengembangan usahatani sayuran organik serta menganalisis dan menetapkan strategi yang dapat diterapkan dalam pengembangan usahatani sayuran organik berdasarkan faktor internal dan eksternal kelompok tani Cepoko Mulyo. 


\section{METODE PENELITIAN}

Penelitian dilakukan di kelompok tani Cepoko Mulyo, Dukuh Pandansari, Desa Wonodoyo, Kecamatan Cepogo, Kabupaten Boyolali, Jawa Tengah pada bulan Februari sampai dengan April 2018. Teknik pengambilan partisipan menggunakan teknik prosedur sengaja (purposive), dengan 9 orang partisipan terdiri dari 1 orang ketua kelompok tani, 2 orang seksi pembelian dan penjualan, 2 orang adminitrasi keuangan, 2 orang inspektoral internal, 1 orang penyuluh pertanian dan 1 orang petugas Pengendali Organisme Pengganggu Tumbuhan (POPT).

Jenis penelitian ini adalah penelitian deskriptif dengan pendekatan manajemen strategi. Data Primer adalah data yang diperoleh melalui catatan kegiatan usahatani, observasi, wawancara langsung menggunakan kuesioner. Pengumpulan data dilakukan melalui wawancara menggunakan kuesioner yang sudah disiapkan. Data sekunder adalah data yang diperoleh dari manajemen internal, studi literatur, media cetak dan elektronik, dan informasi lain yang terkait dengan topik penelitian (Sugiyono, 2010)

Data-data yang diperoleh selanjutnya dianalisis dan diolah secara kuantitatif dan kualitatif melalui tiga tahapan. Pertama, tahap pengumpulan data dianalisis menggunakan matriks Internal Factor Evaluation (IFE) dan External Factor Evaluation (EFE). Kedua, tahap pencocokkan data dianalisis dengan matriks Internal External (IE) dan matriks Strength, Weakness, Opportunities, and Threats (SWOT). Ketiga, tahap pengambilan keputusan menggunakan Quantitative Strategic Planning Matrix (QSPM).

\section{HASIL DAN PEMBAHASAN}

\section{Identifikasi Faktor Internal}

Faktor-faktor internal untuk mengidentifikasi kekuatan dan kelemahan kelompok tani Cepoko Mulyo antara lain manajemen, pemasaran, keuangan, produksi, serta sistem informasi manajemen. Kekuatan dan kelemahan kelompok tani Cepoko Mulyo ditampilkan pada Table 1.

Table 1. Strengths and Weaknesses of Cepoko Mulyo Farmers' Group

\begin{tabular}{|c|c|c|}
\hline Faktor Strategis Internal & Kekuatan & Kelemahan \\
\hline Manajemen & $\begin{array}{l}\text { - Hubungan ketua kelompok tani dan } \\
\text { anggota baik } \\
\text { - Sertifikat organik, label produk, } \\
\text { Standard Operating Procedur (SOP), } \\
\text { dan Good Agricultural Practices } \\
\text { (GAP) }\end{array}$ & \\
\hline Pemasaran & $\begin{array}{l}\text { - Perencanaan pemasaran } \\
\text { - Promosi sayuran organik }\end{array}$ & - Belum memiliki pasar tetap \\
\hline Keuangan & & - Keterbatasan modal kelompok tani \\
\hline Produksi & $\begin{array}{l}\text { - Kualitas produk sayuran terjamin } \\
\text { - Jenis sayuran bermacam-macam } \\
\text { - Lokasi yang sesuai untuk budidaya } \\
\text { - sayuran organik } \\
\text { - Perencanaan pemasaran } \\
\text { - Pengawasan dalam pascapanen }\end{array}$ & $\begin{array}{l}\text { - Belum memiliki gudang pasca } \\
\text { panen }\end{array}$ \\
\hline $\begin{array}{l}\text { Sistem Informasi } \\
\text { manajemen }\end{array}$ & & $\begin{array}{l}\text { - Penerapan dan pengelolaan sistem } \\
\text { informasi yang belum baik }\end{array}$ \\
\hline
\end{tabular}

Sumber: Data Primer, 2018

\section{Identifikasi Faktor Eksternal}

Faktor-faktor eksternal untuk mengidentifikasi peluang dan ancaman kelompok tani Cepoko Mulyo antara lain ekonomi, sosial budaya, teknologi, pemerintah dan persaingan. Peluang dan ancaman kelompok tani Cepoko Mulyo disajikan pada Table 2. 
Table 2. Opportunities and Threats of Cepoko Mulyo Farmers' Group

\begin{tabular}{|c|c|c|}
\hline $\begin{array}{l}\text { Faktor Strategis } \\
\text { Eksternal }\end{array}$ & Peluang & Ancaman \\
\hline Ekonomi & $\begin{array}{l}\text { - Pasar produk sayuran organik yang luas } \\
\text { baik di dalam maupun luar negeri } \\
\text { - Kerjasama dengan pemerintah dan swasta } \\
\text { dalam bantuan modal } \\
\text { - Kemampuan menciptakan pasar dan } \\
\text { bersaing dengan produk lain }\end{array}$ & $\begin{array}{l}\text { - Harga produk sayuran organik yang } \\
\text { masih mahal }\end{array}$ \\
\hline Sosial dan budaya & $\begin{array}{l}\text { - Tingkat kesadaran masyarakat untuk hidup } \\
\text { sehat atau kembali ke alam } \\
\text { - Pertanian organik membantu memperbaiki } \\
\text { ekosistem } \\
\text { - Adanya Asosiasi Pertanian Organik }\end{array}$ & $\begin{array}{l}\text { - Dampak perubahan iklim } \\
\text { - Tingkat serangan Organisme } \\
\text { Pengganggu Tanaman (OPT) }\end{array}$ \\
\hline Teknologi & $\begin{array}{l}\text { - Teknologi dan ilmu pengetahuan tentang } \\
\text { sayuran organik semakin canggih }\end{array}$ & \\
\hline Pemerintah & $\begin{array}{l}\text { - Kebijakan pemerintah mendukung } \\
\text { pengembangan usahatani sayuran organik }\end{array}$ & \\
\hline Persaingan & & $\begin{array}{l}\text { - Kemudahan konsumen mendapatkan } \\
\text { barang subtitusi. } \\
\text { - Tingkat persaingan tinggi dengan } \\
\text { usahatani lainnya }\end{array}$ \\
\hline
\end{tabular}

Sumber : Data Primer, 2018

\section{Analisis Matriks IFE}

Matrik IFE digunakan untuk mengetahui seberapa besar pengaruh dari faktor-faktor internal usahatani sayuran organik. Pemberian bobot dan rating dilakukan oleh 9 orang partisipan, sehingga diperoleh nilai tertimbang dari faktor internal berdasarkan nilai rata-rata hasil para partisipan. Nilai total skor pada matriks ini merupakan hasil perkalian rata-rata bobot dan rata-rata rating masing-masing faktor strategis internal usahatani sayuran organik (Setyorini et al., 2016). Berdasarkan hasil perhitungan Matriks IFE pada Table 3, total skor untuk kekuatan sebesar 2,146 dan total skor kelemahan sebesar 0,592, sehingga diperoleh total skor matriks IFE sebesar 2,737 yang menunjukkan kemampuan kelompok tani Cepoko Mulyo dapat menggunakan kekuatan yang dimiliki secara maksimal dalam meminimalkan kelemahan yang ada (David, 2006). Pada Table 3 diketahui faktor kekuatan utama kelompok tani Cepoko Mulyo adalah pada variabel jenis sayuran yang bermacam-macam dengan skor tertinggi sebesar 0,287 . Jenis sayuran yang dimiliki kelompok tani Cepoko Mulyo sebanyak 30 jenis yang sudah disertifikasi organik antara lain sawi sendok, kubis, brokoli, tomat, cabe. Pada Tahun 2018, kelompok tani Cepoko Mulyo berencana menambah produk yang akan dibudidayakan serta didaftarkan sertifikasi organik yaitu beet root. Aneka produk sayuran yang dihasilkan menjadikan kekuatan utama kelompok tani Cepoko Mulyo. Faktor kelemahan utama kelompok tani Cepoko Mulyo berada pada variabel penerapan dan pengelolaan sistem informasi yang belum baik dengan nilai skor 0,172 . Hal ini dapat diartikan bahwa kelompok tani merupakan suatu organisasi kecil yang terdiri dari perkumpulan petani yang memiliki misi yang sama serta memiliki keterbatasan penggunaan teknologi informasi manajemen dalam kegiatan usahatani sayuran organik. Kelemahan ini juga sejalan dengan penelitian Firmansyah (2016), kelemahan kelompok tani dalam memanfaatkan sistem informasi yang belum baik karena keterbatasan sumber daya manusia yang ada di kelompok dalam menguasai teknologi di bidang manajemen sistem informasi pertanian. Lokasi kelompok tani Cepoko Mulyo yang berada di bawah kaki gunung Merapi serta memiliki ketinggian 1200-1700 m dpl (meter di atas permukaan laut) juga menjadi penyebab susahnya mendapatkan sinyal seluler yang menjadi kendala penggunaan teknologi informasi pertanian di era modern saat ini. 
Table 3. Analysis of IFE Matrix of Cepoko Mulyo Farmers' Group

\begin{tabular}{|c|c|c|c|}
\hline $\begin{array}{l}\text { Faktor Strategis Internal } \\
\text { (1) }\end{array}$ & $\begin{array}{c}\text { Rerata Bobot } \\
\text { (2) }\end{array}$ & $\begin{array}{c}\text { Rerata Rating } \\
\text { (3) }\end{array}$ & $\begin{array}{c}\text { Skor } \\
(4)=(2) \mathrm{x}(3)\end{array}$ \\
\hline \multicolumn{4}{|l|}{ Kekuatan } \\
\hline Hubungan ketua kelompok tani dan anggota baik & 0,084 & 3,4 & 0,286 \\
\hline Kualitas produk sayuran terjamin & 0,075 & 3,0 & 0,225 \\
\hline Jenis sayuran yang bermacam-macam & 0,087 & 3,3 & $\mathbf{0 , 2 8 7}$ \\
\hline Lokasi yang sesuai untuk budidaya sayuran organik & 0,070 & 3,4 & 0,238 \\
\hline Sertifikasi organik, label produk, SOP, dan GAP & 0,073 & 3,6 & 0,263 \\
\hline Perencanaan tanam yang baik & 0,068 & 3,3 & 0,224 \\
\hline Perencanaan pemasaran & 0,072 & 2,9 & 0,209 \\
\hline Promosi sayuran organik & 0,076 & 2,7 & 0,205 \\
\hline \multirow[t]{2}{*}{ Pengawasan dalam pasca panen } & \multirow{2}{*}{\multicolumn{2}{|c|}{ Total Skor Kekuatan }} & 0,209 \\
\hline & & & 2,146 \\
\hline \multicolumn{4}{|l|}{ Kelemahan } \\
\hline Belum memiliki pasar yang tetap & 0,076 & 1,7 & 0,129 \\
\hline Belum memiliki gudang pasca panen & 0,089 & 1,6 & 0,142 \\
\hline Keterbatasan modal kelompok tani & 0,074 & 2,0 & 0,148 \\
\hline \multirow[t]{2}{*}{$\begin{array}{l}\text { Penerapan dan pengelolaan sistem informasi yang } \\
\text { belum baik }\end{array}$} & 0,086 & 2,0 & 0,172 \\
\hline & \multicolumn{2}{|c|}{$\begin{array}{r}\text { Total Skor Kelemahan } \\
\text { Total Matrik IFE }\end{array}$} & $\begin{array}{l}0,592 \\
2.737\end{array}$ \\
\hline
\end{tabular}

Sumber : Data Primer, 2018

\section{Analisis Matriks EFE}

Matrisk EFE digunakan untuk mengetahui seberapa besar pengaruh dari faktor-faktor eksternal usahatani sayuran organik. Pemberian bobot dan rating dilakukan oleh 9 orang partisipan, sehingga diperoleh nilai tertimbang dari faktor eksternal berdasarkan nilai rata-rata hasil para partisipan. Nilai total skor pada matriks ini merupakan hasil perkalian rata-rata bobot dan rata-rata rating masing-masing faktor strategis eksternal usahatani sayuran organik (Setyorini et al., 2016).

Berdasarkan hasil perhitungan pada Table 4, total skor peluang sebesar 1,652 dan total skor ancaman sebesar 1,233 sehingga diperoleh total skor matriks EFE sebesar 2,884 yang menunjukkan kemampuan kelompok tani Cepoko Mulyo dapat memanfaatkan peluang yang dimiliki secara maksimal serta dapat meminimalkan ancaman yang ada. Pada Table 4 diketahui faktor peluang utama kelompok tani Cepoko Mulyo adalah pada variabel adanya Asosiasi Pertanian Organik dengan skor tertinggi yaitu 0,239. Dengan memanfaatkan peluang adanya Asosiasi Pertanian Organik diharapkan permasalahan yang dihadapi oleh kelompok tani
Cepoko Mulyo dalam hal pemasaran produk dapat diatasi dengan bekerjasama dalam memasarkan produk yang dihasilkan. Adanya Asosiasi Pertanian Organik juga berfungsi untuk bertukar informasi dalam usahatani sayuran organik yang dilakukan kelompok tani. Faktor ancaman utama kelompok tani Cepoko Mulyo berada pada variabel tingkat persaingan tinggi dengan usahatani lainnya dengan nilai skor 0,234 . Hal ini terjadi karena kelompok tani Cepoko Mulyo baru mendapatkan sertifikasi organik pada tahun 2016 sehingga dalam memasarkan produk yang dihasilkan harus bersaing dengan produk yang dihasilkan oleh kelompok tani lainnya yang sudah terlebih dahulu melakukan kegiatan usahatani organik. Persaingan yang dialami oleh kelompok tani Cepoko Mulyo yaitu dalam hal pemasaran, selain bersaing dengan produk organik juga harus bersaing dengan produk sayuran konvensional yang beredar di pasaran dalam jumlah yang banyak. Dengan adanya ancaman ini kelompok tani Cepoko Mulyo seharusnya dapat memanfaatkan peluang dengan adanya Asosiasi Petani Sayuran Organik dalam meminimalkan ancaman tersebut. 
Table 4. Analysis of EFE Matrix of Cepoko Mulyo Farmers' Group

Faktor Strategis Eksternal Rerata Bobot

Rerata Rating

(3)

(1)

\section{Peluang}

Kebijakan pemerintah mendukung pengembangan usahatani sayuran organik

Pasar produk sayuran organik yang luas baik di dalam maupun luar negeri

Kerjasama dengan pemerintah dan swasta dalam bantuan modal

Teknologi dan ilmu pengetahuan tentang sayuran organik semakin canggih

Kemampuan menciptakan pasar dan bersaing dengan produk lain

Tingkat kesadaran masyarakat untuk hidup sehat atau kembali ke alam

Pertanian organik membantu memperbaiki ekosistem

Adanya Asosiasi Pertanian Organik

\section{Ancaman}

Kemudahan Konsumen mendapatkan produk subtitusi

Tingkat persaingan tinggi dengan usahatani lainnya

Dampak perubahan fenomena iklim

(2)

0,079

$$
2,9
$$

0,077

0,077

$$
2,7
$$

0,075

0,075

$$
2,6
$$

3,3

3,1

0,077

Total Skor Peluang

Tingkat serangan OPT

Harga produk sayuran organik yang masih mahal Kurangnya pengetahuan konsumen tentang label organik

$\begin{array}{lll}0,079 & 2,8 & 0,221 \\ 0,078 & 3,0 & \mathbf{0 , 2 3 4} \\ 0,060 & 3,1 & 0,186 \\ 0,056 & 3,1 & 0,174 \\ 0,071 & 3,1 & 0,220 \\ 0,076 & 2,6 & 0,198\end{array}$

Total Skor Ancaman Total Matrik EFE

0,221

0,186

0,174

0,198

1,233

2,884
0,239

Skor

$(4)=(2) \times(3)$

0,229

0,162

0,208

0,233

0,195

0,186

0,201

1,652

Sumber : Data Primer, 2018

\section{Analisis Matriks IE}

\begin{tabular}{cc|c|c|}
\multicolumn{1}{c}{} & \multicolumn{2}{c}{ Total Nilai IFE } \\
Rata-rata \\
$(2.0-2.99)$ \\
\end{tabular}

Figure 1. Analysis of IE matrix Cepoko Mulyo Farmer Group

Kegunaan matriks IE yaitu untuk mengetahui posisi kelompok tani Cepoko Mulyo saat ini dan memilih strategi yang akan ditetapkan. Matriks IE pada Figure 1 ditentukan dari hasil total skor matriks IFE dan matriks EFE. Hasil total skor matrik IFE adalah 2,737 dan total skor matriks
EFE adalah 2,884. Selanjutnya hasil matriks IFE dan EFE diletakkan pada kolom matriks IE, dengan nilai total matriks IFE pada sumbu horizontal $X$ dan nilai total matriks EFE pada sumbu vertikal Y. Berdasarkan hasil analisis matriks IE, didapat usahatani sayuran organik 
kelompok tani Cepoko Mulyo berada pada sel V yaitu mempertahankan dan memelihara (Hold and Maintain). Strategi yang cocok digunakan pada sel ini yaitu dengan penetrasi pasar dan pengembangan produk.

\section{Table 5. Analysis SWOT of Cepoko Mulyo Farmers' Group}

\begin{tabular}{|c|c|c|}
\hline $\begin{array}{r}\text { Faktor Internal } \\
\text { (IFE) }\end{array}$ & $\begin{array}{l}\quad \text { STRENGHT-S } \\
\text { 1. Hubungan ketua kelompok tani } \\
\text { dan anggota baik. } \\
\text { 2. Kualitas produk sayuran } \\
\text { terjamin. } \\
\text { 3. Jenis sayuran yang bermacam- } \\
\text { macam. } \\
\text { 4. Lokasi yang sesuai untuk } \\
\text { budidaya sayuran organik. } \\
\text { 5. Sertifikasi organik, label } \\
\text { produk, SOP dan GAP. } \\
\text { 6. Perencanaan tanam yang baik. } \\
\text { 7. Perencanaan pemasaran. } \\
\text { 8. Promosi sayuran organik. } \\
\text { 9. Pengawasan dalam pasca panen }\end{array}$ & $\begin{array}{l}\text { WEAKNESS-W } \\
\text { 1. Belum memiliki pasar yang } \\
\text { tetap. } \\
\text { 2. Belum memiliki gudang } \\
\text { pasca panen. } \\
\text { 3. Keterbatasan modal } \\
\text { kelompok tani. } \\
\text { 4. Penerapan dan pengelolaan } \\
\text { sistem informasi yang belum } \\
\text { baik. }\end{array}$ \\
\hline $\begin{array}{l}\text { OPPORTUNITIES-O } \\
\text { 1. Kebijakan pemerintah } \\
\text { mendukung pengembangan } \\
\text { usahatani sayuran organik. } \\
\text { 2. Pasar produk sayuran organik } \\
\text { yang luas baik di dalam maupun } \\
\text { luar negeri. } \\
\text { 3. Kerjasama dengan pemerintah } \\
\text { dan swasta dalam bantuan modal. } \\
\text { 4. Teknologi dan ilmu pengetahuan } \\
\text { tentang sayuran organik semakin } \\
\text { canggih. } \\
\text { 5. Kemampuan menciptakan pasar } \\
\text { dan bersaing dengan produk lain. } \\
\text { 6. Tingkat kesadaran masyarakat } \\
\text { tentang gaya hidup sehat atau } \\
\text { kembali ke alam. } \\
\text { 7. Pertanian organik membantu } \\
\text { memperbaiki ekosistem. } \\
\text { 8. Adanya Asosiasi Pertanian } \\
\text { Organik. }\end{array}$ & $\begin{array}{l}\text { Strategi S-O } \\
\text { Mempertahankan dan } \\
\text { meningkatkan kualitas produk yang } \\
\text { dihasilkan. } \\
\text { (S2, S3, S4, S5, S6, S9, O4, O5, O6, } \\
\text { O7) } \\
\text { Melakukan kerjasama dengan } \\
\text { kelompok tani lainnya dalam } \\
\text { pemasaran produk. } \\
\text { (S1, S2, S3, S5, S7, S8, O2, O5, } \\
\text { O8) }\end{array}$ & $\begin{array}{l}\text { Melakukan kerjasama dengan } \\
\text { pemerintah baik pusat maupun } \\
\text { daerah dalam pemasaran produk. } \\
(\mathrm{W} 1, \mathrm{~W} 2, \mathrm{~W} 3, \mathrm{O} 1, \mathrm{O} 2, \mathrm{O} 3, \mathrm{O} \text {, } \\
\mathrm{O} 6)\end{array}$ \\
\hline $\begin{array}{l}\text { THREATS-T } \\
\text { 1. Kemudahan konsumen } \\
\text { mendapatkan barang subtitusi. } \\
\text { 2. Tingkat persaingan tinggi dengan } \\
\text { usahatani lainnya. } \\
\text { 3. Dampak perubahan iklim. } \\
\text { 4. Tingkat serangan OPT. } \\
\text { 5. Harga produk sayuran organik } \\
\text { yang masih mahal. } \\
\text { 6. Kurangnya pengetahuan } \\
\text { konsumen tentang label organik. }\end{array}$ & $\begin{array}{l}\text { Penggunaan screen house agar } \\
\text { produk tetap terjamin kualitasnya. } \\
\text { (S1, S2, S3, S4, S5, S6, T3, T4, T5) }\end{array}$ & $\begin{array}{l}\text { Strategi W-T } \\
\text { Melakukan riset pasar dalam } \\
\text { memantau perkembangan } \\
\text { pemasaran produk, harga serta } \\
\text { tingkat persaingan. } \\
(\mathrm{W} 1, \mathrm{~W} 2, \mathrm{~W} 4, \mathrm{~T} 1, \mathrm{~T} 2, \mathrm{~T} 5, \mathrm{~T} 6)\end{array}$ \\
\hline
\end{tabular}

Analisis Matriks SWOT (Strenght, Weakness, Opportunities, Treatht)

Gabungan pencocokkan data antara faktor internal (kekuatan dan kelemahan) dan faktor eksternal (peluang dan ancaman), terdapat empat tipe strategi SO (kekuatan-peluang/strengthopportunities), strategi WO (kelemahanpeluang/weaknesses-opportunities), strategi ST 
(kekuatan-ancaman/strength-threats), dan strategi WT (kelemahan-ancaman/weaknesses-threats) seperti ditunjukkan pada Table 5. Berdasarkan Table 5 dapat dirumuskan 5 altenatif strategi pada kelompok tani Cepoko Mulyo yaitu:

\section{a. Strategi S-O (Strenght-Opportunities)}

Strategi S-O yaitu strategi yang menggunakan kekuatan internal kelompok tani untuk memanfaatkan peluang eksternal. Altenatif strategi yang dapat digunakan dengan mempertahankan dan meningkatkan kualitas produk yang dihasilkan agar dapat masuk dan bersaing di pasaran. Diharapkan dengan produk yang berkualitas, sedikit demi sedikit produk yang dihasilkan dapat masuk dan bersaing di pasaran serta memiliki daya tarik bagi konsumen dalam hal pemasaran produk yang dihasilkan.

Strategi lain yang dapat digunakan yaitu dengan melakukan kerjasama dengan kelompok tani lainnya yang sudah terlebih dahulu memiliki pangsa pasar dalam pemasaran produk. Tujuan kerjasama ini adalah untuk memperkenalkan produk yang dihasilkan oleh anggota kelompok tani Cepoko Mulyo agar tidak semuanya dipasarkan di pasar tradisional dan bersaing dengan produk konvensional.

\section{b. Strategi W-O (Weaknesses-Opportunities)}

Strategi WO yaitu strategi yang bertujuan untuk memperbaiki kelemahan internal dengan memanfaatkan peluang eksternal. Altenatif strategi yang digunakan yaitu melakukan kerjasama dengan pemerintah baik pusat maupun daerah dalam pemasaran produk. Kelompok tani Cepoko Mulyo belum memiliki pangsa pasar yang tetap dalam memasarkan produk yang dihasilkan sehingga harus dilakukan kerjasama pemasaran dengan pemerintah melalui event-event yang diadakan pemerintah pusat maupun daerah. Dengan mengikuti event-event ini diharapkan produk yang dihasilkan dapat diketahui oleh banyak orang. Kerjasama juga diharapkan berupa pelatihan tentang bagaimana produk yang dihasilkan dapat bersaing di pasaran dan sesuai dengan keinginan konsumen.

\section{c. Strategi S-T (Strenghts-Threats)}

Strategi ST yaitu strategi yang menggunakan kekuatan internal untuk menghindari atau mengurangi pengaruh dari ancaman eksternal secara langsung. Altenatif strategi yang ditawarkan yaitu penggunaan screen house agar produk terjamin kualitasnya. Penggunaan screen house diharapkan dapat meminimalkan ancaman yang disebabkan oleh perubahan iklim dan tingkat serangan OPT yang mengakibatkan gagal panen maupun penurunan kualitas produk yang dihasilkan sehingga tidak dapat bersaing di pasaran serta tidak diminati konsumen.

\section{d. Strategi W-T (Weaknesses-Threats)}

Strategi WT yaitu taktik defensif yang diarahkan pada pengurangan kelemahan internal dan menghindari ancaman eksternal. Altenatif strategi yang diberikan yaitu melakukan riset pasar dalam memantau perkembangan pemasaran produk, harga, serta tingkat persaingan. Strategi ini dapat dilakukan dengan menjalin kerjasama dengan perusahaan-perusahaan untuk mencari dan mendapatkan informasi pasar pertanian organik. Riset pasar berguna dalam pemasaran produk agar dapat bersaing di pasaran dengan produk yang diinginkan konsumen, harga yang ditawarkan pesaing, dan tingkat persaingan produk yang ada di pasaran.

\section{Analisis Quantitative Strategic Planning Matrix (QSPM)}

Analisis QSPM merupakan tahap terakhir dari analisis formulasi strategi, pada tahap ini altenatif strategi yang ditawarkan didasarkan pada analisis SWOT yang telah dilakukan. Proses pemilihan prioritas strategi dilakukan melalui penilaian 9 orang partisipan yang memiliki kedudukan masing-masing dalam kelompok tani Cepoko Mulyo. Setiap partisipan memberikan nilai daya tarik terhadap altenatif strategi yang diberikan, selanjutnya hasil dari kesembilan orang partisipan dirata-rata untuk memperoleh urutan prioritas strategi yang dapat diterapkan. Nilai TAS (Total Attractive Score) yang dihasilkan lalu diurutkan berdasarkan besar nilainya. Urutan nilai TAS menggambarkan urutan prioritas strategi yang dapat dilaksanakan oleh kelompok tani. Strategi dengan nilai TAS tertinggi adalah strategi yang paling diprioritaskan oleh kelompok tani untuk mengembangkan usahatani sayuran organik (Zulkarnaen dan Sutopo, 2013). Urutan prioritas dapat dilihat pada Table 6 . 
Table 6. Analysis QSP Matrix of Cepoko Mulyo Farmers' Group

\begin{tabular}{lcc}
\multicolumn{1}{c}{ Altenatif Strategi } & Total TAS & Prioritas \\
\hline Mempertahankan dan meningkatkan kualitas produk yang dihasilkan & 6,454 & 2 \\
Melakukan kerjasama dengan kelompok tani lainnya dalam pemasaran produk & 6,377 & 3 \\
$\begin{array}{l}\text { Melakukan kerjasama dengan pemerintah pusat maupun daerah dalam } \\
\text { pemasaran produk }\end{array}$ & 6,469 & 1 \\
$\begin{array}{l}\text { Penggunaan Screen house agar produk tetap terjamin kualitasnya } \\
\text { Melakukan riset pasar dalam memantau perkembangan pemasaran produk, } \\
\text { harga serta tingkat persaingan }\end{array}$ & 6,140 & 5 \\
\hline
\end{tabular}

Sumber : Data Primer, 2018

Berdasarkan Table 6 urutan prioritas strategi yang disarankan dengan merujuk pada total TAS mulai dari nilai tertinggi sampai terendah adalah:

1. Melakukan kerjasama dengan pemerintah baik pusat maupun daerah dalam pemasaran produk (TAS $=6,469)$

2. Mempertahankan dan meningkatkan kualitas produk yang dihasilkan (TAS $=6,454$ )

3. Melakukan kerjasama dengan kelompok tani lainnya dalam pemasaran produk (TAS = 6,377)

4. Melakukan riset pasar dalam memantau perkembangan pemasaran produk, harga serta tingkat persaingan (TAS $=6,164$ )

5. Pengunaan screen house agar produk tetap terjamin kualitasnya (TAS $=6,140$ )

\section{KESIMPULAN DAN SARAN}

\section{Kesimpulan}

Berdasarkan hasil penelitian analisis strategi pengembangan usahatani sayuran organik kelompok tani Cepoko Mulyo Desa Wonodoyo, Kecamatan Cepogo, Kabupaten Boyolali dapat disimpulkan faktor internal yang menjadi kekuatan utama dalam pengembangan usahatani sayuran organik kelompok tani Cepoko Mulyo yaitu jenis sayuran yang bermacam-macam, kelemahan utama yaitu penerapan dan pengelolaan sistem informasi yang belum baik. Faktor eksternal yang menjadi peluang utama yaitu adanya Asosiasi Pertanian Organik, ancaman utama yaitu tingkat persaingan tinggi dengan usahatani lainnya. Strategi yang didapat berdasarkan nilai TAS tertinggi yaitu dengan melakukan kerjasama dengan pemerintah baik pusat maupun daerah dalam hal pemasaran produk.

\section{Saran}

Saran yang diberikan untuk kelompok tani Cepoko Mulyo yaitu dapat memanfaatkan kekuatan dengan mempertahankan jenis sayuran yang dihasilkan serta memanfaatkan adanya Asosiasi Pertanian Organik untuk meminimalkan ancaman adanya persaingan dengan usahatani lain, serta dapat memperbaiki kelemahan sistem informasi dengan mengikuti jaman yang serba digital. Melakukan kerjasama dengan pemerintah baik pusat maupun daerah dalam pemasaran, dengan mengikuti event atau pameran yang diadakan pemerintah. Pemerintah pusat maupun daerah diharapkan bersedia untuk membantu memasarkan produk yang dihasilkan oleh kelompok tani ini dengan mengikutsertakan dalam event atau acara yang ada, serta melakukan pelatihan dan pendampingan dalam kegiatan usahatani sayuran organik dari proses perencanaan sampai dengan pemasaran produk.

\section{DAFTAR PUSTAKA}

Adiyoga, W. 1999. Pola Pertumbuhan Produksi Beberapa Jenis Sayuran Di Indonesia. Jurnal Hortikultura, 9(3), 258-265. Retrieved from https://www.scribd.com/doc/17558351/PolaPertumbuhan-Produksi-Beberapa-JenisSayuran-Di-Indonesia

Baity, S., Purnomo, D., \& Sulistyo, T. D. 2015. Budidaya Organik Kedelai Pada Sistem Agroforestri Menggunakan Pupuk Hayati. Caraka Tani: Journal of Sustainable Agriculture, $\quad 30(1), \quad 7-12$. https://doi.org/10.20961/carakatani.v30i1.118 40

David, F. R. 2006. Manajemen Strategis: Konsep \& Teori Ed. 10. Jakarta: Salemba Empat.

Dlamini, D. F., \& Kongolo, M. 2014. Resource Use Efficiency in Organic Vegetable Production: A Case Study of Manzini Region, Swaziland. Journal of Agricultural Studies, 2(2), 52. https://doi.org/10.5296/jas.v2i2.5958 
Effendi, A. L. 2015. Segmentasi Konsumen Sayuran Organik pada Yogya Dept. Store Kota Bandung Tahun 2014. Jurnal Manajemen Bisnis Telekomunikasi Dan Informatika, 2(1), 10-17. Retrieved from http://repository.telkomuniversity.ac.id/pustak a/files/100103/jurnal_eproc/segmentasi-

konsumen-sayuran-organik-pada-yogya-deptstore-kota-bandung-2014.pdf

Firmansyah, Y. B. 2016. Strategi Pengembangan Usahatani Sayuran Organik Kelompok Tani Bangkit Merbabu di Kabupaten Semarang Provinsi Jawa Tengah = Development Strategy of Organic Vegetable Farming Farmers Group "Bangkit Merbabu" in Semarang Regency Central Java. Program Studi Agribisnis FPB-UKSW. Retrieved from http://repository.uksw.edu/handle/123456789/ 11932

Gribaldi. 2009. Pertanian Organik dan Teknologi Pendukungnya. AgronobiS, 1(2), 19-24. https://doi.org/1979 - 8245X

Hubeis, M., Najib, M., Widyastuti, H., \& Wijaya, N. H. 2013. Strategi Produksi Pangan Organik Bernilai Tambah Tinggi yang Berbasis Petani ( A Strategy of Organic Vegetable Production With a Farmer-Based Premium Price ). Jurnal Ilmu Pertanian Indonesia, 18(3), 194-199. Retrieved

from http://journal.ipb.ac.id/index.php/JIPI/article/ view/8397

Irawati, \& Salamah, Z. 2013. Pertumbuhan Tanaman Kangkung Darat (Ipomoea reptans Poir.) Dengan Pemberian Pupuk Organik Berbahan Dasar Kotoran Kelinci. Jurnal Bioedukatika, $\quad 1(1), \quad 1-96$. https://doi.org/10.26555/bioedukatika.v1i1.40 79

Khalimi, K. 2010. Pemanfaatan Ragi (Saccaromyces sp.) Dalam Pengendalian Penyakit Tumbuhan Yang Ramah Lingkungan. BUMI LESTARI JOURNAL OF ENVIRONMENT, 10(2), 215-221.

Lathifah, M. N., Supriyono, S., \& Mujiyo, M. 2017. Respon Garut Terhadap Jumlah Benih Dan Dosis Pupuk Organik. Caraka Tani: Journal of Sustainable Agriculture, 32(2), 101-107.

https://doi.org/10.20961/carakatani.v32i2.144 50
Mayrowani, H. 2012. Pengembangan Pertanian Organik Di Indonesia The Development Of Organic Agriculture In Indonesia. Forum Penelitian Agro Ekonomi, 30(2), 91-108. https://doi.org/10.21082/fae.v30n2.2012.91108

Muljaningsih, S. 2011. Preferensi Konsumen dan Produsen Produk Organik di Indonesia. WACANA, Jurnal Sosial Dan Humaniora, 14(4), 1-5. Retrieved from http://wacana.ub.ac.id/index.php/wacana/artic le/view/266

Putra, P. S. D., Ambarawati, I. G. A. A., \& Yusuf, R. P. 2015. Manajemen Pemasaran Sayur Organik (Studi Kasus pada P4S Eka Setia Lestari di Desa Bangli, Kecamatan Baturiti, Kabupaten Tabanan). E-Journal Agribisnis Dan Agrowisata (Journal of Agribusiness and Agritourism), 4(2), 107-116. Retrieved from https://ojs.unud.ac.id/index.php/JAA/article/vi ew/17393

Roosany, T. I. N., Setiawan, I. G., Putra, A., \& Astiti, N. W. S. 2014. Strategi Pengembangan Usaha Sayur Organik pada CV Golden Leaf Farm Bali Strategy of Organic Vegetable Development at CV Golden Leaf Farm Bali Pendahuluan. JURNAL MANAJEMEN AGRIBISNIS (Journal Of Agribusiness Management), 2(1), 61-75. Retrieved from https://ojs.unud.ac.id/index.php/agribisnis/arti cle/view/9947

Setyorini, H., Effendi, M., \& Santoso, I. 2016. Analisis Strategi Pemasaran Menggunakan Matriks SWOT dan QSPM ( Studi Kasus : Restoran WS Soekarno Hatta Malang ) Marketing Strategy Analysis Using SWOT Matrix and QSPM ( Case Study: WS Restaurant Soekarno Hatta Malang ). Industria: Jurnal Teknologi Dan Manajemen Agroindustri, 5(1), 46-53. https://doi.org/10.21776/ub.industria.2016.00 5.01 .6

Silitonga, J., \& Salman, S. 2014. Analisis Permintaan Konsumen Terhadap Sayuran Organik Di Pasar Modern Kota Pekanbaru. DINAMIKA PERTANIAN, 29(1), 79-86. Retrieved from http://journal.uir.ac.id/index.php/dinamikapert anian/article/view/862

Suardika, I. M. P., Ambarawati, I. G. A. A., \& 
Sukaatmadja, I. P. 2014. Analisis Perilaku Konsumen terhadap Keputusan Pembelian Sayur Organik CV Golden Leaf Farm Bali Analysis of Consumer Behavior Toward Organic Vegetable Purchasing Decisions CV Golden Leaf Farm Bali Pendahuluan. Jurnal Manajemen Agribisnis, 2(1), 1-10. Retrieved from

https://ojs.unud.ac.id/index.php/agribisnis/arti cle/view/9942

Sugiyono. 2010. Metode Penelitian Kuantitatif Kualitatif dan $R \& D$. Bandung: Alfabeta.

Sulistyana, P., Mulyo, J. H., Sosial, J., Pertanian, E., Pertanian, F., Mada, U. G., ... Mada, U. G. 2014. Konsumsi Beras Organik Pada Tingkat Rumah Tangga Di Kota Yogyakarta. Agro Ekonomi, 24(1), 25-34. https://doi.org/10.22146/agroekonomi.17357
Sutanto, R. 2002. Penerapan Pertanian Organik, Pemasyarakatan \& Pengembangannya. Jakarta: Kanisius.

Yanti, R. 2005. Aplikasi teknologi pertanian organik: penerapan pertanian organik oleh petani padi sawah Desa Sukorejo Kabupaten Sragen, Jawa Tengah. Jakarta: PascasarjanaUI.

Zulkarnaen, H. O., \& Sutopo, S. 2013. Analisis Strategi Pemasaran Pada Usaha Kecil Menengah (UKM) Makanan Ringan ( Studi Penelitian UKM Snack Barokah di Solo ). Diponegoro Journal of Management, 2(3), 108-120. Retrieved from https://ejournal3.undip.ac.id/index.php/djom/a rticle/view/3212 